\title{
Experiencing Creativity in the Organization: From Individual Creativity to Collective Creativity
}

\author{
Satu Parjanen \\ Lappeenranta University of Technology, \\ Lahti School of Innovation, Lahti, Finland
}

\author{
satu.parjanen@lut.fi
}

\begin{abstract}
Creativity is a component that enhances the ability of organizations to retain their competitive advantage as well as to stay ahead of their competitors. For creative organizations, the ideas and insights of their employees are of crucial importance. Most of the creativity research concentrates only on individual aspects of creativity. This paper also stresses the collective aspect of creativity in the organization. It studies how employees experience creativity and in what way they would support creative processes in their organization. The research material is from an action-based research project that tries to reveal innovation potential in all levels of the organization. According to the results, there is room for creativity in every job. However, creativity and especially the collective aspect of creativity in the organization are undervalued, though most of the work in the organization needs the expertise and creativity of many employees. This study also introduces the employee-driven way to support collective creativity in the organization.
\end{abstract}

Keywords: creativity, collective creativity, employee, knowledge, innovation, diversity

\section{Introduction}

In today's business world, innovations provide companies with major opportunities and advantages. Innovation can be defined as the outcome of a set of activities that use knowledge to create new value to those benefiting from its use (de Sousa, 2006). It is commonly accepted that innovations are brought forward in an interactive process of knowledge generation and application. Organizations need to generate knowledge, facilitate the sharing of knowledge, and apply the knowledge so that the organization can generate innovation. Innovative organizations use knowledge creatively. Creativity is the component that enhances the organizations' ability to retain their competitive advantage as well as to stay ahead of their competitors. For this type of organizations, the ideas and insights of their employees are of crucial importance. However, much innovation potential remains unexploited because organizations assign the responsibility of getting new and implementable ideas only to the R\&D functions (Axtell et al., 2000; Chesbrough, 2003; Tidd,

Material published as part of this publication, either on-line or in print, is copyrighted by the Informing Science Institute. Permission to make digital or paper copy of part or all of these works for personal or classroom use is granted without fee provided that the copies are not made or distributed for profit or commercial advantage AND that copies 1) bear this notice in full and 2) give the full citation on the first page. It is permissible to abstract these works so long as credit is given. To copy in all other cases or to republish or to post on a server or to redistribute to lists requires specific permission and payment of a fee. Contact Publisher@InformingScience.org to request redistribution permission.
Bessant, \& Pavitt, 2001).

To remain competitive, organizations need their employees to be actively involved in their work and try to generate novel and suitable products, processes, and approaches (Shalley \& Gilson, 2004). Many achievements in companies involve collaboration between many creative individuals, each with varying knowledge, skills, life experi- 
ence, perspectives, and expertise. These kinds of collectives can tackle multi-faceted challenges that cannot be met individually. Nowadays we do not only speak about individual creativity but also about collective creativity (Hargadon \& Beckhy, 2006; Sawyer, 2006). Collective creativity can be defined as creative processes leading to creative products that are the results of interaction between two or more people. In collective creativity, it is impossible to trace the source of new ideas to an individual. Instead, creative activity emerges from the collaboration and contribution of many individuals, thereby blurring the contribution of specific individuals in creating ideas.

In this study, the focus is on investigating the concepts of creativity and collective creativity in the context of promoting the employees' creativeness and innovativeness. The research problem is: how to enhance collective creativity in the organization. The research questions are: how do the employees themselves perceive creativity in their work place, and in what way would they support creativity and especially collective creativity in the organization? The case study is based on empirical data from an action research based process conducted in one private company.

\section{The Creation of New Knowledge}

An organization's success and survival depend on its capability to create new knowledge and then innovation. Knowledge is an organization's most valuable resource because it embodies intangible assets, routines, and creative processes that are difficult to imitate. According to Nonaka and Takeuchi (1995), successful companies are those that consistently create new knowledge, disseminate it widely throughout the organization, and rapidly include it in new products. These characteristics define a "knowledge creating" company, whose business consists solely of continuous innovation. The key to success in a knowledge company is to build the intellectual capital that will create core competencies and distinctive products that will lead to superior results. Everybody is a knowledge worker in a knowledge creating company, where inventing new knowledge is a way of behaving. The central activity of a knowledge-creating company is to make personal knowledge available to others. This takes place continuously and at all levels of an organization.

A constructivist view of knowledge focuses on the intraorganizational processes through which new knowledge is generated and has highlighted the importance of both social practices within which new knowledge is created and social interaction through which new knowledge emerges (Tsoukas, 2009). More specifically, Nonaka and his associates (Nonaka \& Takeuchi, 1995; Nonaka \& Toyama, 2005) have proposed the socialization externalization combination internalization (SECI) model of knowledge creation. The core idea of the model is that "knowledge is created through the interaction between tacit and explicit knowledge" (Nonaka \& Takeuchi, 1995, p. 62). Knowledge creation involves the creation of new concepts through dialogue and the management of conversations. Moreover, they have highlighted the use of figurative language and the combination of concepts to create new ones, in different parts of the knowledge creation process. For example, through metaphors people put together what they know but cannot yet put in words. (Nonaka \& Takeuchi, 1995, p. 86; von Krogh, Ichijo, \& Nonaka, 2000.)

Uotila, Melkas, and Harmakkorpi (2005) have offered an extended SECI-model. They emphasized the need to deepen the future orientation of the SECI model by adding two new knowledge conversion modes into the model. The added modes focus on self-transcending knowledge, a concept introduced by Scharmer (2001), who defined it as "tacit knowledge prior to its embodiment" - the ability to sense the presence of potential, to see what does not yet exist. Two additional modes were named the visualization and potentialization modes. The visualization mode is the conversion from self-transcending to tacit knowledge through visions, feelings, a mental model, etc. The potentialization mode is the conversion from tacit to self-transcending knowledge by sensing the future potentials and seeing what does not yet exist. 
Most innovation happens at the boundaries between disciplines or specializations (Carlile, 2002, 2004; Johansson, 2004; Leonard, 1995). Carlile (2002, 2004) has shown how the creation of new knowledge is facilitated when knowledge boundaries are crossed. Working across boundaries is a key ingredient in competitive advantage and also explains why innovation is difficult to create and maintain. The level of novelty will determine the complexity of the knowledge boundary. As the level of novelty increases, the associated path-dependent nature of knowledge may have negative effects, making knowledge sharing and creation difficult. Leonard (1995) considers mechanisms for importing and absorbing knowledge, transferring knowledge across the organization, and developing new knowledge bases. She also introduces the notion of "creative abrasion", where different knowledge bases are brought together through open discussion between individuals with different perspectives. If the potential conflict is successfully managed, it could lead to new, creative and exciting ideas. However, creative abrasion does not happen automatically. It is designed into the organization, for example by maintaining a diverse mixture of different skills among employees.

\section{The Creativity Approach}

Creativity is closely related to knowledge (Leonard \& Sensiper, 1998). From the innovation perspective, knowledge provides the organization with the potential for novel action, and the process of constructing novel actions often entails finding new uses or new combinations of previously disparate ideas (Hargadon \& Sutton, 1997; Weick, 1979). In organizations, creativity is the process through which new ideas that make innovation possible are developed. Current views on organizational creativity appear to focus largely on outcomes or creative products. A creative product has been defined as one that is both novel and original and potentially useful or appropriate to the organization (Amabile, 1996; Mumford \& Gustafson, 1998). Additionally, at least for companies, creative ideas must have utility. They must constitute an appropriate response to fill a gap in the production, marketing, or the administrative processes of the organization. Organizational creativity is the creation of a valuable, useful new product, service, idea, procedure, or a process by individuals working together in a complex social system. Therefore, creativity could be seen as an important organizational capability (Amabile, 1998), a possible source of organizational effectiveness (Woodman, Sawyer, \& Griffin, 1993), and a source of competitive advantage (Leonard \& Sensiper, 1998).

Research on creativity at the organizational level can in general be divided into two categories: the characteristics of the members of the organization and the characteristics of the organization that facilitate and nurture employee creativity. An employee's engagement in innovative work behavior requires the employee to be both able and willing to be innovative. Employees may exhibit creativity by developing new knowledge, advancing technologies, or by making process improvements that will lead to innovations. Employee innovativeness can be defined as engagement in innovative behavior related to the innovation process (de Jong \& Kemp, 2003; Parzefall, Seeck, \& Leppänen, 2008). Amabile (1997) writes that expertise, creative thinking skills, and motivation, when mixed together, identify the level of creativity within an individual. The expertise component includes memory for factual knowledge, technical proficiency, and special talents in the target domain. Creative thinking means that an individual is able to see things from more than one perspective and is able to question the existing working models. If problems are solved the way they always have been solved, it blocks creativity and prevents new ideas from penetrating. Creativity and innovativeness require a certain level of internal force that pushes the individual to persevere in the face of challenges in creative work (Shalley \& Gilson, 2004). The task motivation component determines what a person will actually do (Amabile, 1997). 
According to Nayak (2008), a major limitation of the individual creativity research is its reliance on studies of the psychology of the creative person. Researchers have uncritically drawn on creativity studies that are based on artists, poets, and children to see whether organizations have an impact on creativity. By posing the question in this manner, researchers have axiomatically constructed the organizational setting as inhibiting creativity. In other words, they assume that outside the organizational environment, creativity would have flourished. Nayak investigated creativity in a large UK supermarket retailer undergoing major change and transformation. His findings show that in a creative organization, managers rely on their own values and beliefs. Awareness of personal morality as an important dimension of experiencing organizational creativity can contribute towards a better understanding of how and why a reconstruction of an organization along creative lines may succeed or fail.

In many studies managerial behaviours have been connected to employees' creative performance. Leaders may support employees' creativity by allocating resources. One of the most valuable resources that leaders may allocate in order to foster creativity is time (Mumford \& Gustafson, 1988). Access to funds, materials, facilities, and information also supports creativity (Amabile et al., 1996). Leaders can also influence creativity in the way they design work groups. According to research (Amabile, Conti, Coon, Lazenby, \& Herron, 1996; Milliken \& Martins, 1996), work groups conducive to creativity have diversely skilled members, an openness to new ideas, interpersonal trust, commitment to the work, and communication where members constructively challenge each other's ideas. In particular, diversity in group composition provides potential for innovation (e.g., Johansson, 2004; Paulus, 2000). Innovations involve the challenge of enabling renewal based on diversity and facilitating the integration of knowledge in a creative way. Job characteristics that relate to creativity, including complexity, autonomy, variety, and feedback, also support creativity at the work place. Also supportive leadership is positively related to employee creativity (Oldham \& Cummings, 1996). Leaders may provide encouragement for creativity by valuing individuals' contributions and showing confidence in the work group (Amabile et al., 1996).

Organizational factors such as structure and culture may play a more important role in predicting the realization of innovations than in influencing the employee tendency to produce creative and innovative ideas (Axtell et al., 2000). Open, flexible structures, decentralized decision-making, and low hierarchical levels favor innovation. Organic structures allow diversity and individual expression and they are well suited to the initiation phase of the innovation processes. The possibility for employees to interact with people from different departments could provide information that is beneficial for the generation of ideas. In particular, information from employees with more diverse expertise provides connections to more remote facts and perspectives (Madjar, 2005). Flexible structures are also often more conducive to open and effective organizational and interdepartmental communication. On the other hand, some level of stability, clarity, and coordination is needed. If formal mechanisms are absent, communication comes to depend solely on the discretionary and ad hoc effort of the organization members, which may not be sufficient (Parzefall et al., 2008.)

The concept of climate is used to refer to specific facets of organizational culture, for example a climate for psychological safety, service, initiative and innovation (Patterson et al., 2005). Psychological safety refers to a shared belief that an organization is a safe environment for taking interpersonal risks without needing to fear negative consequences (Edmondson, 1999). Empirical studies suggest that organizations with a climate for psychological safety are particularly conducive to innovativeness (Baer \& Frese, 2003). The mechanism through which this occurs includes reduced risks through presenting new ideas, a higher level of job involvement, and better team learning. Morrison and Phelps (1999) suggest that an organizational climate that is considered safe and encourages risk-taking is important in motivating individuals to take initiative. Initiative 
plays an important role in the innovation process: individuals with initiative are more likely to take an active approach to work, to go beyond what is formally required in their jobs and to have the persistence to follow their creative ideas through to implementation (Miron, Erez, \& Naveh, 2004).

According to Hargadon and Bechky (2006), the literature on creativity in organizations is less concerned with action and interaction at the collective level than creativity at the individual level. Collective creativity occurs when social interactions between individuals trigger new interpretations and new discoveries of distant analogies that the individuals involved could not have generated by thinking alone. Such an approach differs from the existing research on creativity and innovation along two dimensions. Rather than focusing on the group and organizational variables that make up the ongoing context for creativity, this perspective recognizes the fleeting coincidence of behaviors that triggers moments when creative insights emerge. And rather than viewing this eureka moment as the sole province of individual cognition, this perspective focuses on those insights that emerge in the interactions between individuals.

Table 1 introduces literature related to collective creativity. These studies highlight the importance of group and organizational creativity as well as the relationship between the different levels of creativity within the organization. For example, Woodman et al. (1993) give a central place to group creative performance in their model of organizational creativity. Oldham and Cummings (1996) highlight the organizational context that enhances creative achievement. They conclude that to promote organizational creativity, management should consider both personal and contextual factors in order to increase creativity. According to Bharadwaj and Menon (2000), both the individual and organizational creativity mechanisms can lead to innovation in companies. Based on the above studies, collective creativity does not diminish the importance of individual creativity. Without individual creativity, there is no context for collective creativity and vice versa. As Chaharbaghi and Cripps (2007) note, it is the balance between the individual and the societal that makes collective creativity meaningful. Collective creativity is not simply the sum of individual creativities, but rather it intensifies and multiplies them in meeting a challenge of common concern.

Table 1: Literature related to collective creativity

\begin{tabular}{|l|l|l|}
\hline Study & Data & Results \\
\hline $\begin{array}{l}\text { Woodman, Sawyer } \\
\text { and Griffin (1993) }\end{array}$ & Theoretical analysis & $\begin{array}{l}\text { Full understanding of creativity in complex social settings } \\
\text { requires going beyond a focus on individual actors and } \\
\text { examining the situational context within which the crea- } \\
\text { tive process takes place. A variety of social and contextual } \\
\text { influences affect creativity at the group and organizational } \\
\text { levels. Many of these influences either constrain or en- } \\
\text { hance the creative performance of individuals and groups. }\end{array}$ \\
\hline $\begin{array}{l}\text { Oldham and Cum- } \\
\text { mings (1996) }\end{array}$ & $\begin{array}{l}\text { The research was } \\
\text { conducted in two } \\
\text { manufacturing facili- } \\
\text { ties that produced } \\
\text { component parts for } \\
\text { technical equipment } \\
\text { (171 employees). }\end{array}$ & $\begin{array}{l}\text { According to the results, employees produced the most } \\
\text { creative work when they had appropriate creative-relevant } \\
\text { characteristics, worked on complex, challenging jobs, and } \\
\text { were supervised in supportive, non-controlling fashion. }\end{array}$ \\
\hline $\begin{array}{l}\text { Drazin, Glynn, and } \\
\text { Kazanjian (1999) }\end{array}$ & Theoretical analysis & $\begin{array}{l}\text { Authors' proposal sustains the relevance of continuous } \\
\text { interaction processes in creativity aimed at establishing } \\
\text { the common patterns of reference and shared meanings } \\
\text { necessary to overcome moments of crisis in collective } \\
\text { actions. }\end{array}$ \\
\hline
\end{tabular}




\begin{tabular}{|l|l|l|}
\hline Study & Data & Results \\
\hline Bharadwaj and & $\begin{array}{l}\text { Data were gathered } \\
\text { through a mail survey } \\
\text { of key respondents in } \\
750 \text { business units of } \\
500 \text { corporations. }\end{array}$ & $\begin{array}{l}\text { The study finds that organizational creativity mechanism } \\
\text { and individual creativity mechanism can lead to innova- } \\
\text { tion in companies. The study suggests that high levels of } \\
\text { organizational creativity mechanism led to significantly } \\
\text { superior innovation performance than low levels of organ- } \\
\text { izational and individual creativity mechanism. }\end{array}$ \\
\hline Taggar (2002) & $\begin{array}{l}\text { The performance of } \\
\text { 94 groups on 13 dif- } \\
\text { ferent open-ended } \\
\text { tasks was studied. }\end{array}$ & $\begin{array}{l}\text { The study shows that although it is necessary for a group } \\
\text { to contain members who are creative, team creativity- } \\
\text { relevant processes that emerge as part of group interaction } \\
\text { are also important. Indeed, without this latter type of be- } \\
\text { havior, the benefits of putting together a group of highly } \\
\text { creative individuals are neutralized. }\end{array}$ \\
\hline $\begin{array}{l}\text { Hargadon and Be- } \\
\text { chky (2006) }\end{array}$ & $\begin{array}{l}\text { The model is ground- } \\
\text { ed in observations, } \\
\text { interviews, informal } \\
\text { conversations, and } \\
\text { archival data gathered } \\
\text { in intensive field } \\
\text { studies of work in } \\
\text { professional service } \\
\text { firms. }\end{array}$ & $\begin{array}{l}\text { The study confirms the relevance of investigating the pro- } \\
\text { cesses that lead to significant and valuable collective crea- } \\
\text { tive results and demonstrates that four sets of interrelating } \\
\text { activities foster collective creativity (help seeking, help } \\
\text { giving, reflective reframing and reinforcing). }\end{array}$ \\
\hline $\begin{array}{l}\text { Bissola and Impera- } \\
\text { tori (2011) }\end{array}$ & $\begin{array}{l}\text { A grounded research } \\
\text { design through six } \\
\text { focus groups attended } \\
\text { by 24 managers from } \\
\text { 17 Italian fashion and } \\
\text { design firms and 12 } \\
\text { academics. }\end{array}$ & $\begin{array}{l}\text { The results confirm that creativity is not only about crea- } \\
\text { tive genius, and designing potential for creativity is not a } \\
\text { matter of linear correlation but includes a more sophisti- } \\
\text { cated and integrative approach according to which indi- } \\
\text { vidual creative skills, team dynamics and organizational } \\
\text { solutions interact with each other to produce a collective } \\
\text { creative performance. }\end{array}$ \\
\hline
\end{tabular}

\section{CASE STUDY: A Creative Organization}

\section{Methodology}

The case company is a Finnish telecommunications company providing high-quality, state-of-theart voice, data, and mobile communications and TV services to private customers, organizations, and corporations. Over the last decade, the domestic business environment in mobile communications changed. Instead of innovation driven growth, the continuous deregulation of Finnish markets has led to exceptional price competition. The competition in voice call prices has led to decreased revenues, consolidation of players, and even exits from Finnish mobile markets. Decreased revenues in turn have led to cautious and slow investments in new technologies and slow development of new services. Telecommunications companies, like the case company, faced the fact that possibly they cannot charge anything for plain voice calls, so they have to find sound models of how to survive in the future (Janhunen, 2006).

The case company was established shortly before the turn of the millennium, and, in the beginning, the company was owned by approximately 40 Finnish telephone companies located all over the country. Preparations for opening a new, national mobile phone service were made during the year 2000. In 2007, the case company changed from a mobile communications operator into a major telecommunications company. The current company began operating in 2007, when its business operations merged with six telephone companies. Alongside its mobile communications 
business, the company obtained a strong fixed-network business, including voice, data, cable TV, and information security services for both households and companies.

The data used in this study constitutes an action research-based development project called Innovation Catcher, which aims at revealing the hidden innovation potential at the different levels of an organization. Action research as a twofold methodological approach consists of two projects: the action project where action is generated, and the research project that intends to create knowledge about that action (Coughlan \& Coghlan, 2002; Reason \& Bradbury, 2008). The Innovation Catcher project in the case company was a part of a larger development process with the aim of building a more innovative organizational culture in the company. The role of the Catcher project was to find ways to facilitate the employees' creativity and make everybody a knowledge worker in the company.

The research material for this case was gathered at the end of 2008 and the beginning of 2009. The qualitative research methods consist of a semi-structured interview (Table 2), observation of the development sessions, and analysis of group works. The questions were made by several researchers and were based on the literature review. Some of the questions were chosen according to discussions with the representatives of the company. For example, the representatives of the company were talking about a need for a communal innovation culture. So, the researchers decided to include a question concerning how employees understand this kind of culture. As the interview process evolved and the understanding and knowledge of the researchers accumulated, some more specified questions were added to the semi-structured interviews. The researchers of the action research team conducted the interviews and the interviews were anonymous. There were 18 employee level interviewees. The interviewees were purposefully chosen all over the company to get the best possible overview of the ideas of the employees. The researchers made a summary of the main findings of the interviews which they introduced to the company representatives and also to the participants of the Innovation Catcher.

The data were analyzed according to the principles of qualitative content analysis. The coding scheme was derived from the data, previous related studies, and theories. It included categories such as creativity, motivation, organizational culture, expertise, ideation processes, and leadership. During coding more categories were generated or they were divided to several categories. For example, new categories were "help asking" and "help giving" and "expertise" was divided to "internal expertise" and "external expertise". A particular comment or answer was assigned to a single category or it was assigned to more than one category simultaneously. After coding, the properties and dimensions of the categories were explored and relationships between categories were identified. The purpose was to find similarities and differences in the data and produce a condensed description about how creativity is experienced in the organization. In the analysis of the data an especial attention was drawn to the challenges of creativity in the organization. Atlas.ti software was used to help to analyze the data. 
Table 2: Example questions

\begin{tabular}{|c|c|c|}
\hline $\begin{array}{l}\text { Themes of the inter- } \\
\text { view }\end{array}$ & Example questions & References \\
\hline Background data & $\begin{array}{l}\text { What is your job description? } \\
\text { How long have you worked in this or- } \\
\text { ganization? }\end{array}$ & \\
\hline $\begin{array}{l}\text { Communal innovation } \\
\text { culture }\end{array}$ & $\begin{array}{l}\text { How would you define communal in- } \\
\text { novation culture? } \\
\text { What kind of elements does an ideal } \\
\text { working environment have? } \\
\text { How do you motivate yourself? } \\
\text { How would you define creativity? } \\
\text { Do you need creativity in your work? } \\
\text { What kills creativity? }\end{array}$ & $\begin{array}{l}\text { Amabile }(1996,1997,1998) \\
\text { Taggar (2002) } \\
\text { Van der Panne, Van der Beers, and } \\
\text { Kleinknecht (2003) } \\
\text { Miron, Erez, and Naveh (2004) } \\
\text { Shalley and Gilson (2004) }\end{array}$ \\
\hline $\begin{array}{l}\text { Co-operation between } \\
\text { departments }\end{array}$ & $\begin{array}{l}\text { What kind of co-operation is done be- } \\
\text { tween departments? } \\
\text { Are there any problems in knowledge } \\
\text { sharing between departments? What } \\
\text { kind of problems? } \\
\text { How would you develop the co- } \\
\text { operation between departments? }\end{array}$ & $\begin{array}{l}\text { Paulus (2000) } \\
\text { Moanaert, Caeldries, Lievens, and } \\
\text { Wauters. (2000) } \\
\text { Keller (2001) } \\
\text { Bechky (2003) } \\
\text { Anderson, De Dreu, and Nijstad } \\
\text { (2004) } \\
\text { Bhirud, Rodrigues, and Desai (2005) }\end{array}$ \\
\hline $\begin{array}{l}\text { Leadership and man- } \\
\text { agement }\end{array}$ & $\begin{array}{l}\text { Is it possible to manage ideation in the } \\
\text { organization? } \\
\text { Who are the right leaders in innovation } \\
\text { activities? } \\
\text { How do leaders give feedback? } \\
\text { What kind of management style is the } \\
\text { most suitable in supporting innovative } \\
\text { culture? }\end{array}$ & $\begin{array}{l}\text { Mumford and Gustafson (1988) } \\
\text { Oldham and Cummings (1996) } \\
\text { Mumford (2000) } \\
\text { Mumford, Scott, Gaddis, and Strange } \\
\text { (2002) } \\
\text { Viitala (2005) } \\
\text { Gumusluoglu and Ilsev (2008) }\end{array}$ \\
\hline Idea generation process & $\begin{array}{l}\text { Where do the good ideas come from? } \\
\text { How is it possible to develop ideas } \\
\text { further? } \\
\text { How are the personnel motivated to } \\
\text { present ideas? }\end{array}$ & $\begin{array}{l}\text { Amabile }(1996,1997,1998) \\
\text { Bandura (1993) } \\
\text { Axtell et al. (2000) } \\
\text { Bharadwaj and Menon (2000) } \\
\text { Paalanen and Konsti-Laakso (2007) }\end{array}$ \\
\hline
\end{tabular}

In the analysis, three questions emerged: How to support creativity at work? How to manage creativity/innovation? What are the sources of ideas? Based on these questions, the research group and the key persons from the case company planned two development sessions. The interviewees and some of the representatives of the management participated in the sessions. In the development sessions the participants were in an active role. In the first development session the summary of the interviews was presented to the participants as a stimulus for idea generation. In this summary also findings from creativity and innovation literature were provided. The purpose of the first session was to specify the needed development targets related to the aforementioned questions. This was done collectively in groups. The questions were discussed by using the Learning Café method where every group generated ideas for every question. Every question had a separate table where groups visited and wrote their ideas on a big sheet of paper. Every table had a researcher who explained the question and if necessary, facilitated the discussion, for example by summarizing what the previous group had discussed or by asking specified questions. Due to this method, all participants were given the opportunity to actively take part in the discussion and give their opinions or make statements on the topic. At the end of the session, participants voted for the ideas they wanted to develop further in the next session. 
The second session began with a short presentation on the innovation tool that has the purpose of supporting organizations to bring in new ideas from outside. This tool was not aimed at supporting creativity inside the organization, but in some sense it probably affected thinking, because the participants borrowed some elements of the tool into their constructed method. Before the participants planned the method to help idea generation and creativity in the company, they had a small group work about creative problem solving with specific roles. Every group defined their problem and roles by themselves. According to the discussions, those groups where there were participants from different fields succeeded better in developing new approaches to the problem. To facilitate the group work on the idea-generation method, the researchers had made some helpful questions, for instance what kind of roles are needed, what are the advantages of the method, what is the purpose of its use, what kind of problems or challenges there are in the development and use of the method. But the groups also had the possibility not to answer these questions. After the group work there were general discussions about issues that emerged during the group work. The group work sessions were documented and analyzed. The researchers also wrote a report of the sessions.

\section{Employees' Experiences about Creativity in the Organization}

Although the level of creativity required and the importance of creativity can differ depending on the task or job in question, there is room for creativity in almost every job (Shalley \& Gilson, 2004), providing a foundation for organizational creativity and innovation (Amabile, 1997). Only one interviewee in the case company was skeptical about the need for creativity in his/her work. All other interviewees acknowledged the need for creativity in their work. Creativity was needed in every day work, for example when "tailoring the services to fit the customer's needs" or "finding the best practices and implementing them". Challenges that require creativity are (often) complex and ill-defined. One of the interviewees pointed out that creativity is needed to lighten one's own work: "when you are a little bit of a lazy person, you like to develop new ways of making your work easier".

The organizational changes in the company have emphasized the need for creativity in the organization. Even though the changes were considered necessary, they were not always a positive thing for the employees. Organizational changes lessened possibilities for collective activity in the organization because employees were unsure of whom to ask for help or they concentrated only on their own work. One interviewee explained, "I do have ideas, but I won't tell them to anyone”. However, surprisingly many interviewees stressed the need for a positive attitude in complex situations. Attitude was mentioned directly in four interviews. Here are some comments made by the interviewees: “...to survive, I decided to concentrate on work and have a positive attitude" and "It is matter of attitude. Do you complain because you don't want any changes or it is possible to think that there is something good in the changes”. None of the interviewees expressed totally negative or frustrated comments about the organizational changes.

At the time when the current company was founded, creativity and innovativeness were especially needed: "people were employed without clear job descriptions and everybody had to define his/her place in the organization". However, that time was also considered "a fruitful time to change things and do things in a different way". To change things was not necessarily easy to do because "there is a need to hold on to the old and safe practices even if they have not been a functioning solution in the changed situation". In this way, creativity forces individuals to step away from safe and familiar situations and to live with uncertainty (Shalley \& Gilson, 2004).

In the case company, creative ideas came from a range of internal and external sources. The most common answer in the interviews was that everyday situations generate ideas at work and during free time. According to one interviewee, "these ideas do not always relate strictly to one's own work but are probably useful in other parts of the company". Another interviewee described these ideas as a source of incremental innovations: "most of these ideas and innovations are small 
things, like developing every day work routines”. Examples of external sources are seminars and conferences. Also the role of competitors and other stakeholders was acknowledged as a source of useful ideas. Acquiring external knowledge was appreciated: “... it should be encouraged more to be informed about what is happening in this branch”.

According to Amabile et al. (2002), one of the most frequently cited factors necessary for innovativeness is sufficient time to think creatively and explore different perspectives. Nowadays employees are often time constrained, causing them to feel overworked and burned out. The increased workload and keeping with the timetables was seen as especially detrimental to creativity and innovativeness by the interviewees: "...it is really challenging to find the time to be creative because you have to keep to timetables and do routine work". The lack of time was mentioned in every interview. Also the shrinking of the work force in the company placed an extra burden on the remaining employees. According to the interviewees, the motivation in their work comes from "the challenges of the work", "the successes of the work", "feedback", or "when you have the possibility to show your expertise".

Creativity requires expertise. One cannot be truly creative unless one knows a good deal about a particular area (Amabile, 1998). People must actively acquire and work with knowledge if creative problem solutions are to be generated. In fact, one of the most noteworthy characteristics of creative people is that they have a substantial investment in expertise and the ongoing development of expertise (Mumford et al., 2002). Mostly, interviewees pointed to their own expertise rather than external expertise. In the data, there were 15 comments related to individual and five comments to external knowledge. The interviewees acknowledged that "you have to be good at what you are doing" to generate ideas that have utility for the company. Expertise was also seen as important in implementing ideas: "those who decide the further development of ideas should be experts in that area". In this sense, they highlighted previous experience as essential. Also according to the research, solving creative problems collectively in organizations relies on connecting past experiences to the problems of the current situations (Hargadon \& Bechky, 2006; Hargadon \& Sutton, 1997).

This also relates to the employee's absorptive capacity, which comprises "the ability to recognize the value of new, external information, assimilate it, and apply it to commercial ends" (Cohen \& Levinthal, 1990, p. 128). The higher an employee's prior knowledge, the more easily he or she will assimilate new knowledge and utilize it. According to Cohen and Levinthal (1990), high absorptive capacities give rise to creative ideas because they increase an employee's ability to detect new linkages between previously unrelated units of knowledge.

The problems in the case company are highly complex, requiring multiple different forms of expertise; as one interviewee put it, “you can't be expert in every issue”. As a result, creative work often requires collaborative efforts of different compositions. Diversity creates variations, meaning variations in perceptions, values, ideas, opinions, and methods. The only way to move ahead is to perform a continual breakout from the bounds of what was already known. Pursuing diversity is important because it helps generate and sustain organizational heterogeneity that could otherwise disappear out of pressures to conform (Muhr, 2009). According to the interviewees, this kind of heterogeneity existed only in the management level. In different kinds of development groups or teams, the advantage of having employees with different kinds of backgrounds was not used. However, the heterogeneity was considered useful in eight interviews and especially in the development of new products and services: “...I think that it would be most fruitful that people from all over the company would participate ... from sales and the technological department and from all over the company", or "when generating ideas, it would be good to have people with different kinds of expertise”. 
In the interviews, the most important environmental factors affecting creativity were leadership and the organizational atmosphere or culture. These were considered in every interview. The interviewees defined the common innovation culture as the common ideation between employees with diverse expertise, sparring and further development of ideas together. This indicates the wish and need to do things collectively. In the interviews this kind of culture was also related to the solidarity of the employees, which in turn would enhance ideation in the company. In addition to the exposure to diversity, previous research has also shown the importance of familiarity and trust for the effective use of diverse resources for innovative problem solving (Gruenfeld, Mannix, Williams, \& Neale, 1996). At this point, the employees saw that there was no such culture. One interviewee said that "even though some of the changes are needed, they still cause friction because there does not yet exist a shared experience of pulling together."

The advantages of collective activity or the need for that kind of activity was mentioned in every interview. Altogether, there were 35 comments in the interviews which were related directly to collective activity. In addition, there were comments related to help asking and giving, which are considered essential activities in collective creativity (Hargadon \& Bechky, 2006). In over half of the interviews collectivity was mentioned several times during the interview. The interviewees, for example, acknowledged the collective nature of their accomplishments: "not many are capable of thinking about these challenges only by themselves". It was also acknowledged that diversity, meaning, for example, different kinds of expertise, helps the ideation: "others with a little bit different expertise help to see the issue from another perspective". Despite this, the interviewees described creativity as an individual endeavor, noting that "thinking on your own generates ideas", "the poor product manager is thinking all by himself about what to do" or "I'll do these things mostly by myself”. However, the need for collective creativity was obvious.

There were several reasons why there was so little collective activity in the generation and developing of ideas. It was considered time consuming, especially in this geographically distributed company. One interviewee said that, overall, discussion partners from different parts of the company would help in inventing new ideas and solutions, but "it is difficult to find the right person in a distributed organization”. Mixing did occur in some places in the company because people could mix with the help of routine interactions, an open office, or some subunits that were small enough that the same people could see each other daily. In almost every interview, the importance of informal meetings, café breaks, and corridor discussions in generating new ideas and changing the best practices was acknowledged. This indicates that creative ideas may be generated also by accident.

The interviewees felt that creativity or innovativeness were not valued in the strategies of the company, as one interviewee pointed out that "we are not really innovating at all”. Strategy and things related to strategy were mentioned eight times in the data even though it was not asked in the interviews. Nor was creativity encouraged by the leadership. All interviewees acknowledged that leaders have an essential role in facilitating creativity but none of the interviewees could exactly define how this could be done. However, the leaders were seen as having an important role in generating an atmosphere that encourages creativity and innovativeness in the company. This implies that managers, in addition to managing creative individuals in the creative process, should also focus their attention on reinforcing the interactions that turn individuals into creative collectives (Hargadon \& Beckhy, 2006). In all interviews either feedback or motivation was considered as important methods for leaders in creating innovative atmosphere. Among the interviewees it was emphasized that "managing innovation should be done delicately, and you can't lead people in the same way as you lead routine work" and "you should concentrate on the employees as individuals". One of the things that the leaders should offer was resources, such as time. The leaders also have the responsibility to direct ideation to the right things. One possibility to direct creativity was "to develop methods or ways of doing to guide creativity and to pick out those ideas 
that serve the benefit of the company”. Lack of suitable methods was seen in the interviews, because only one interviewee mentioned a method that was used in the company to support idea generation and knowledge sharing between employees.

\section{An Employee-driven Method Facilitating Collective Creativity}

Based on the interviews carried out in the company, a face-to-face method was missing that would concentrate on idea generation, the further development of ideas, and knowledge sharing. The method should also take an advantage of the heterogeneity of the employees and their knowledge in the organization. In the two development sessions, the employees constructed a method to facilitate the collective creativity in the organization (see Figure 1).

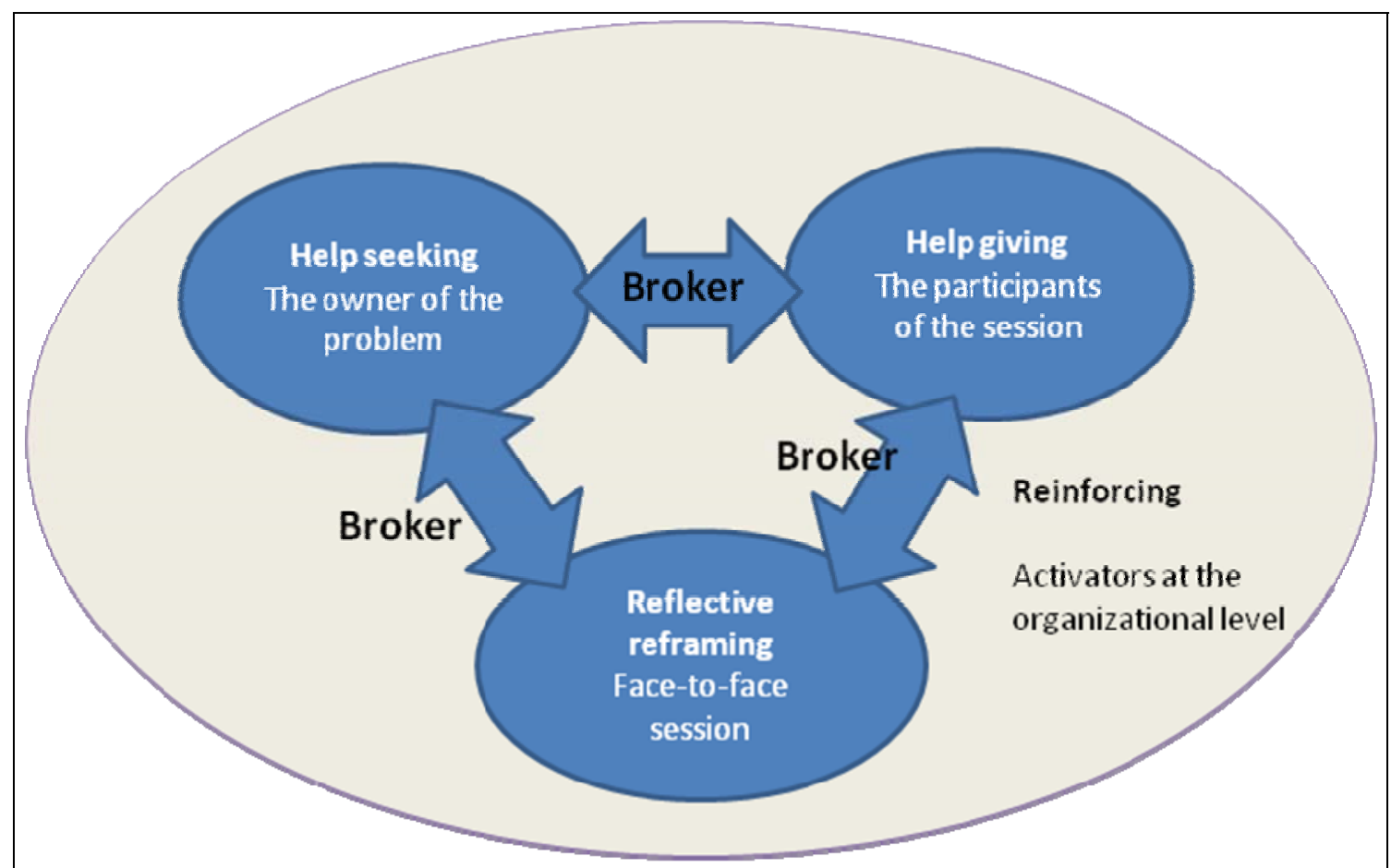

Figure 1: A method to enhance the moments of collective creatluity (modtifedfrom Hangadon and Bechky, ze06)

The constructed method is based on an idea-generation session with defined roles. First, there is the "owner of the problem". Instead of generating the idea or solution alone, he/she seeks help. To give help to the "owner of the problem" the face-to-face idea generation session is conducted with the help of a "broker". The session would be more or less a spontaneous gathering of employees around a particular problem. It is not assigned by leaders, nor need they be involved in the process. It is important to try to organize it within a short period of time. The purpose of the session would be to link the different kinds of knowledge of the organizational members to the current problems faced by the owner of the problem. In the session, the duty of the owner of the problem is to explain the problem and its background to the participants of the session. He is also responsible for developing the idea further after the session.

The session takes place in situations when any one employee does not hold all of the necessary knowledge to construct a creative solution and the potential for a creative solution requires the skills of multiple participants. The session provides a shared context for "creative abrasion" (Leonard, 1995), where employees can interact with each other and engage in dialogue. During this dialogue the participants create new points of view. Eventually they integrate their diverse individual perspectives into a new collective perspective. This dialogue can and indeed should 
involve conflict and disagreement. It is such conflict that pushes the participants to question existing premises and make sense of their experience in a new way (Nonaka \& Takeuchi, 1995, p. 86; von Krogh et al., 2000).

To find creative ideas and fresh possibilities, the participants saw that the problem should not be too familiar to the participants of the session. Diversity will increase the likelihood of creative new knowledge emerging at the session because heterogonous groups of employees can offer applications of expertise from a variety of areas, and this enhances fresh thinking and promotes integration across the traditional borders in the company. That is why the participants of the session should include employees with different kinds of experience and expertise. These "experts" should view the problem from different angles. The creative potential of the experts may actually be dependent on not knowing exactly what is possible. This enables them to think outside the box. Priming can, in fact, reduce creativity, as the participants tend to be preoccupied with already-known solutions (Dahl \& Moreau, 2002; Marsh, Bink, \& Hicks, 1999).

This method has similarities to the model of collective creativity proposed by Hargadon and Beckhy (2006). In their model, there are four sets of interrelating activities that play a role in triggering the moments of collective creativity: (1) help seeking, (2) help giving, (3) reflective reframing, and (4) reinforcing. Help seeking describes activities that occur when an individual who either recognizes or is assigned a problematic situation actively seeks the assistance of others. In the method of the case company, this role is played by the owner of the problem. The broker and others who will take part in the session represent the willing devotion of time and attention to assisting the work of others. The role of the broker, according to the participants of the development sessions, was seen as challenging and essential to the success of the method. The duty of the broker is to build a heterogeneous group around the problem and facilitate its work. He would first prepare the session and then facilitate the idea-generation session. In sum, the duty of the broker is to generate possibilities for help seeking, help giving and reflective reframing activities.

The broker should be partly an outsider to the problem under consideration so he can bring fresh ideas and also help others to think outside the box. The role of the brokers was actually considered so central in the process that they would need some kind of training for their work. The participants also saw that the broker's personal characteristics are relevant to how the broker will succeed in his work. Idea generation sessions are cognitive processes which are strongly moderated by social and motivational factors (Paulus \& Brown, 2007). For example, the social skills of the broker are emphasised in conflict situations (Parjanen, 2012). To help with using the method, there should be a broker pool in the company. There should also be brokers from different departments: production, the technological department, sales, and customer service.

The moments when the participants in social interactions make new sense of what they already know comprise a third important aspect of collective creativity that Hargadon and Beckhy (2006) call reflective reframing. The session itself is the arena where the reflective reframing is possible. When the participants come together in collective problem-solving efforts, one person often has a good understanding of the problematic situation, while others have potentially relevant ideas and experiences to contribute. The locus of creativity in the interaction moves to the collective level when each individual's contributions not only give shape to the subsequent contributions of others but, just as importantly, give new meaning to others' past contributions (Hargadon \& Beckhy, 2006).

According to Hargadon and Beckhy (2006), reinforcing activities are those that support individuals as they engage in help seeking, help giving, and reflective reframing, and as a result, they are also critical in enabling those moments when collective creativity emerges. The social interactions that shape collective efforts involve more than just directly bringing people together; the interactions that give meaning and value to these collective efforts were also important (Hargadon 
\& Bechky, 2006). In the case company, the method was supported by the activators who operate at the organizational level. Their duty is to actively recognize possible problems and enhance the use of different kinds of idea generation and creative methods, including the method constructed in this study. They would also be aware of what kinds of solutions are considered, how they have succeeded, and who have been involved in the process. This kind of activity would increase the organizational memory. It was also noted that the management should support its implementation and use of the method.

Several advantages were seen in this method. The method would increase communication in the organization. It would also teach the employees to think more outside the box, enrich understanding in the company, and add openness to the company. Those who were more optimistic saw that it directs the employees to also think about future potentials and see what does not yet exist. In general, the use of the method would also support innovation activities. Especially the brokers would bring the needed broadmindedness to problem solving, and that would in turn increase the innovativeness of solutions when it is possible to examine an issue from multiple perspectives. The use of the method would also help to see the linkages and causal connections between different issues and problems. The biggest challenge in the development and use of the method was that it might be considered more as nonsense than as real work in the company. The company values more straightforward activities where effectiveness is easily shown. That is why the evaluation of the method and its results were seen as essentially important.

\section{Discussion and Conclusion}

Tidd et al. (2001) emphasize that if an organization innovates by relying only on certain talented individuals, it fails to utilize the creativity of the rest of the organization, not to mention that the others are not committed to developing the ideas further. In the case company, the tightened competition forced it to find new ways to survive. Technological product innovations were not enough to stay in competition; instead, the need for improvements in services and organizational innovations were acknowledged. In this situation, the management wanted to figure out the potential of the employees to participate in innovation activities. According to the results of this study, the employees are willing to participate in innovation activities. However, creativity in the organization does not happen automatically, but it needs to be maintained and supported. This study also supports the idea that creativity exists in different types of work and is not restricted to a specific kind of work, such as work in research and development departments. This means that creative work that benefits the organization may be generated by employees in any position or job and at any level of the organization (Axtell et al., 2000).

Work places are becoming more and more complex, and performing different tasks in the organization requires increasing skills and expertise of many employees. This is particularly highlighted in the telecommunication industry. According to the survey of Leppimäki, Tammi and Meristö (2004), where the Finnish ICT sector's expectations from employees in the near future are examined, new skills required by the ICT firms, besides a specific educational degree, are often qualities of personal nature. Factors such as attitudes, worldview, or personal communication skills are more important than before when firms are recruiting new staff. The desired skills reflect the changes taking place in the ICT sectors' operational environment. Perhaps things like entrepreneurship and communication skills are emphasized just because the ICT firms are operating in a more and more networked world and the focus of the business is shifting towards consumer markets. This shift reflects the need to utilize the creativity of whole of the organization. Growing complexity of problems also implies that employees do not always have the knowledge and individual skills to generate creative solutions on their own. Collective creativity becomes necessary to produce creative outcomes (Hargadon \& Bechky, 2006) to benefit the organization. 
Although individual employees still play an important role in explaining creativity in the organization, today creative outcomes are explained as being the results of social interaction and collaborations (Perry-Smith \& Shalley, 2003; Woodman et al., 1993). Therefore, to promote creativity in an organization, it may be important to understand, catalyze, and support the individual aspect of creativity, as well as the collective aspect. A diversity of perspectives can be a possible source of creativity because innovation is often dependent upon dissimilar knowledge and skills (Boschma, 2005; Leonard, 1995; Parjanen, Harmaakorpi, \& Frantsi, 2010). However, in the case company, creativity is mainly understood as an individual endeavor and the potential of collective creativity was not understood. This was surprising because the employees acknowledged that social interactions facilitate the emergence of new ideas and innovation. They were missing formal and informal ways to share knowledge, develop ideas, and learn from each other. This controversy could partly be explained by the fact that innovation activities were previously carried out only in the R\&D departments and the potential of other employees was not acknowledged. The many organizational changes have also affected at least partly the willingness of the employees to share ideas with other employees.

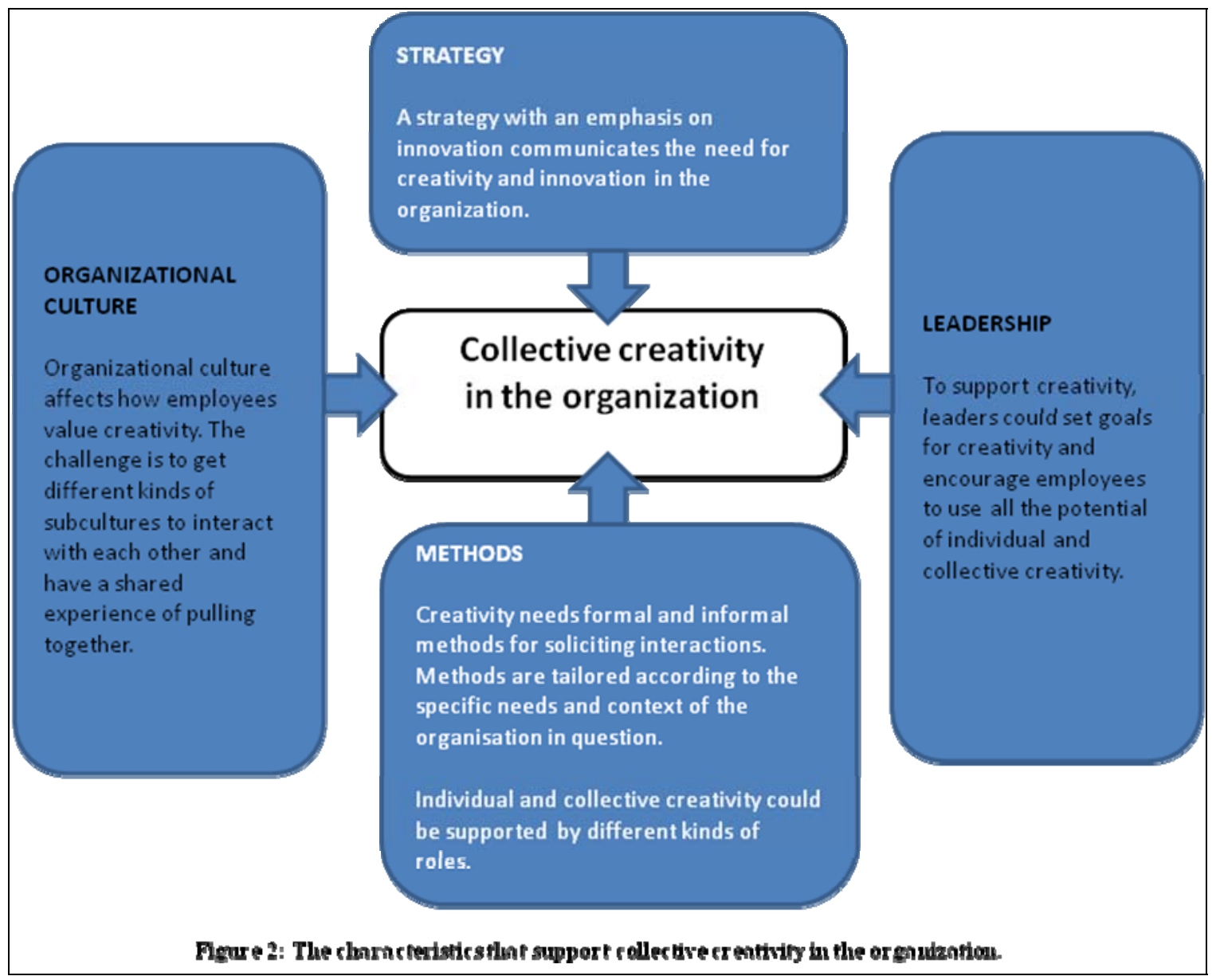

The employees recognized several characteristics to support creativity in the organization, which are described in Figure 2. An organizational strategy gives direction to the activities and development of the organization and its units, departments, teams, and individuals. An explicit innovation strategy or a strategy with a clear focus on innovation is an important factor influencing creativity in organizations. A strategy with an emphasis on innovation communicates the need for creativity and innovation in the organization. To promote collective creativity in the organization, 
the role of the leaders was considered essential in the case organization. Also Amabile (1998) writes that creativity is truly enhanced when an entire organization supports it. In a geographically distributed organization such as the case company, leaders should encourage employees to collaborate so that the expertise behind the creativity is heterogeneous. The leaders' behavior has an effect on how the employees regard creativity. Especially the role of the leaders was considered important for setting goals for creativity. This means that the leadership must be clear about the need for creativity and the types of creativity that best suits the organizational goals. There is also a need to communicate the need for creativity to the employees. Shalley (1995) found in her study that when individuals are told that creativity is important, they are more likely to behave creatively. This implies that if collective creativity is valued in the organization, employees are more like to behave collectively.

In the case company the employees were missing procedures and methods to support individual and, especially, collective creativity and were willing to participate in developing these methods in the company. One way to involve the employees in creative processes is to give them the autonomy to define the ways and methods of how this should be done in the organization. Empirical evidence supports the positive relationship between autonomy and innovation. Autonomy and control over one's work have been found to correlate positively with employee engagement in innovative behaviors (Axtell et al., 2000; Shalley, Gilson, \& Blum, 2000). The employees may also be considered experts of their own work and that way they are the best experts in defining the ways to support creativity at an individual and collective level.

Organizations need to be able to capitalize the diversity among their employees. However, organizations may face barriers to tapping into the diversity of their employees. Issues such as geographic distance, differences in organizational subcultures, and the lack of awareness of others with similar interests render, for example, idea generation difficult (Lesser \& Fontaine, 2004). In order to create possibilities for collective creativity, it could also be beneficial to have different kinds of roles in the organization. In the case organization, a special brokerage function was developed to connect different employees, groups, or departments and make them aware of the interests and difficulties of the other group and transfer best practices (Burt, 2004). This study implies that there is a need for brokers acting in a bridging role not only outside the organization but also inside the organization. It was also acknowledged that the role of the broker is demanding and should be supported by an activator at the organizational level.

In the future studies, it is relevant to study how the ideas of the employees were implemented in the company. Quite soon after the end of Innovation Catcher, the company had large organizational changes where, for example, those who participated in the project were relocated. The case company also gained 200 new employees as a result of the acquisition. This has probably affected how the results of Innovation Catcher have been implemented. However, the case company has continued to focus on well-being at work and employee motivation. The goal is to work towards creating and maintaining a strong and coherent internal culture. It has enhanced its leadership model, which builds on the current organization by adding more detail to role, responsibility, and task descriptions. It has also developed a model of "company peers", which has similarities with the brokers and activators of the constructed model. Peers are a staff network of volunteers who advise their peers, channel information, organize events, and work towards improving team spirit. It would be interesting to study the roles of the company peers and define what kind of brokerage functions they probably have.

\section{Acknowledgements}

The author wishes to thank the European Regional Development Fund and the Regional Council of Päijät-Häme for the opportunity of presenting their research in Interdisciplinary Journal of Information, Knowledge, and Management. 


\section{References}

Amabile, T. (1996). Creativity in context. Boulder, CO: Westview Press.

Amabile, T. (1997). Motivating creativity in organizations: On doing what you love and loving what you do. California Management Review, 40(1), 39-58.

Amabile, T. (1998). How to kill creativity. Harvard Business Review, 76, 76-87.

Amabile, T., Conti, R., Coon, H., Lazenby, J., \& Herron, M. (1996). Assessing the work environment for creativity. Academy of Management Journal, 39(5), 1154-1184.

Amabile, T., Hadley, C. N., \& Kramer, S. J. (2002). Creativity under the gun. Special issue on the innovative enterprise: turning ideas into profits. Harvard Business Review, 80(8), 52-61.

Anderson, N., De Dreu, C. K. W., \& Nijstad, D. A. (2004). The routinization of innovation research: a constructively critical review of the state-of-the-science. Journal of Organizational Behavior, 25, 147172.

Axtell, C., Holman, D., Unsworth, K., Will, T., Waterson, P., \& Harrington, E. (2000). Shopfloor innovation: facilitating the suggestion and implementation of ideas. Journal of Occupational and Organizational Psychology, 39, 599-617.

Baer, M., \& Frese, M. (2003). Innovation is not enough: Climates for initiative and psychological safety, process innovations, and firm performance. Journal of Organizational Behavior, 24(1), 45-69.

Bandura, A. (1993). Perceived self-efficacy in cognitive development and functioning. Educational Psychologist, 28(2), 117-148.

Bechky, B. (2003). Sharing meaning across occupational communities: The transformation of understanding on a production floor. Organization Science, 14(3), 312-330.

Bharadwaj, S., \& Menon, A. (2000). Making innovation happen in organizations: Individual creativity mechanism, organizational creativity mechanism or both? Journal of Product Innovation Management, 17, 424-434.

Bhirud, S., Rodrigues, L., \& Desai, P. (2005). Knowledge sharing practices in km: A case study in Indian software subsidiary. Journal of Knowledge Management Practice, 6.

Bissola, R., \& Imperatori, B. (2011). Organizing individual and collective creativity: Flying in the face of creativity clichés. Creativity and Innovation Management, 20(2), 77-89.

Boschma, R. (2005). Proximity and innovation: A critical assessment. Regional Studies, 39, 61-74.

Burt, R. (2004). Structural holes and good ideas. American Journal of Sociology, 110, 349-399.

Carlile, R. (2002). A pragmatic view of knowledge and boundaries: Boundary objects in new product development. Organization Science, 13, 442-455.

Carlile, R. (2004). Transferring, translating, and transforming: An integrative framework for managing knowledge across boundaries. Organization Science, 15, 555-568.

Chaharbaghi, K., \& Cripps, S. (2007). Collective creativity: wisdom or oxymoron? Journal of European Industrial Training, 31(8), $626-638$.

Chesbrough, H. (2003). Open innovation. The new imperative for creating and profiting from technology. Boston: Harvard Business School Press.

Cohen, W., \& Levinthal, D. (1990). Absorptive capacity: A new perspective on learning and innovation. Administrative Science Quarterly, 35, 128-152.

Coughlan, P., \& Coghlan, D. (2002). Action research for operations management. International Journal of Operations \& Production Management, 22(2), 220-240.

Dahl, D., \& Moreau, P. (2002). The influence and value of analogical thinking during new product ideation. Journal of Marketing Research, 39(2), 47-60. 
de Jong, J. P. J., \& Kemp, R. (2003). Determinants of co-workers' innovative behaviour: An investigation into knowledge intensive services. International Journal of Innovation Management, 7(2), 189-212.

de Sousa, M. (2006). The sustainable innovation engine. VINE: The Journal of Information and Knowledge Management Systems, 36(4), 398-405.

Drazin, R., Glynn, M., \& Kazanjian, R. (1999). Multilevel theorizing about creativity in organizations: A sensemaking perspective. Academy of Management Review, 24(2), 286-307.

Edmondson, A. (1999). Psychological safety and learning behaviour in work teams. Administrative Science Quarterly, 44, 350-383.

Gruenfeld, D., Mannix, E., Williams, K., \& Neale, M. (1996). Group composition and decision making: How member familiarity and information distribution affects process and performance. Organizational Behavior and Human Decision Processes, 67, 1-15.

Gumusluoglu, L., \& Ilsev, A. (2009). Transformational leadership, creativity, and organizational innovation. Journal of Business Research, 62, 461-473.

Hargadon, A., \& Bechky, B. (2006). When collections of creatives become creative collectives: A field study of problem solving at work. Organization Science, 17(4), 484-500.

Hargadon, A., \& Sutton, R. (1997). Technology brokering and innovation in a product development firm. Administrative Science Quarterly, 42, 716-749.

Janhunen, J. (2006). Mobile services market in Finland. In S. Luukainen (Ed.), Innovation in telecommunications. Proceedings of the Research Seminar on Telecommunications Business (pp. 5-10). Publications in Telecommunications Software and Multimedia. Helsinki University of Technology: Espoo.

Johansson, F. (2004). The Medici effect: Breakthrough insights at the intersection of ideas, concepts and cultures. Boston: Harvard Business School Press.

Keller, R. (2001). Cross-functional project groups in research and new product in research and new product development: Diversity, communications, job stress, and outcomes. Academy of Management Journal, 44(3), 547-555.

Leonard, D. (1995). Wellsprings of knowledge. Building and sustaining the sources of innovation. Boston: Harvard Business School Press.

Leonard, D., \& Sensiper, S. (1998). The role of tacit knowledge in group innovation. California Management Review, 40, 112-132.

Leppimäki, S., Tammi, M., \& Meristö, T. (2004). Professional skills in the ICT industry - Turbulent times resulting contradictions and new combinations. In T. Leino, T. Saarinen, \& S. Klein (Eds), Proceedings of the Twelfth European Conference on Information Systems (pp. 1029-1039). Turku: Turku School of Economics and Business Administration.

Lesser, E., \& Fontaine, M. (2004). Overcoming knowledge barriers with communities of practice: Lessons learned through practical experience. In P. Hildred, \& C. Kimble (Eds.), Knowledge networks. Innovation through communities of practice (pp. 14-23). Hershey: Idea Group Publishing.

Madjar, N. (2005). The contributions of different groups of individuals to employees' creativity. Advances in Developing Human Resources, 7(2), 182-206.

Marsh, R., Bink, M., \& Hicks, J. (1999). Conceptual priming in a generative problem solving task. Memory and Cognition, 27(2), 355-363.

Milliken, F. J., \& Martins, L. L. (1996). Searching for common threads: Understanding the multiple effects of diversity in organizational groups. The Academy of Management Review, 21(2), 402-433.

Miron, E., Erez, M., \& Naveh, E. (2004). Do personal characteristics and cultural values that promote innovation, quality, and efficiency compete or complement each other? Journal of Organizational Behavior, 25(2), 175-199. 
Moenaert, R., Caeldries, F., Lievens, A., \& Wauters, E. (2000). Communication flows in international product innovation teams. Journal of Product Innovation Management, 17(5), 360-377.

Morrison, E., \& Phelps, C. (1999). Taking charge at work: Extra-role efforts to initiate workplace change. Academy of Management Journal, 42, 403-419.

Muhr, S. (2009). Wound, interrupted -On the vulnerability of diversity management. Doctoral dissertation, Copenhagen Business School, Department of Management, Politics and Philosophy.

Mumford, M. (2000). Managing creative people: Strategies and tactics for innovation. Human Resource Management Review, 10(3), 313-351.

Mumford, M., \& Gustafson, S. (1988). Creativity syndrome: Integration, application and innovation. Psychological Bulletin, 103, 27-43.

Mumford, M., Scott, G., Gaddis, B., \& Strange, J. (2002). Leading creative people: Orchestrating expertise and relationships. The Leadership Quarterly, 13, 705-750.

Nayak, A. (2008). Experiencing creativity in organisations: A practice approach. Long Range Planning, 41, 420-439.

Nonaka, I., \& Takeuchi, H. (1995). The Knowledge-creating company. New York: Oxford University Press.

Nonaka, I., \& Toyama, R. (2005). The theory of the knowledge-creating firm: Subjectivity, objectivity and synthesis. Industrial Corporate Change, 14, 419-436.

Oldham G., \& Cummings, A. (1996). Employee creativity: Personal and contextual factors at work. Academy of Management Journal, 39, 607-634.

Paalanen, A., \& Konsti-Laakso, S. (2007). Introducing new methods for organizational innovativeness the case of innovation catcher. Proceedings of the 8th international CINet conference, 7-11 September 2007, Göteborg, Sweden.

Parjanen, S. (2012). Innovation sessions as sources of new ideas. International Journal of Innovation and Learning, 11(4), 352-368.

Parjanen, S., Harmaakorpi, V., \& Frantsi, T. (2010). Collective creativity and brokerage functions in heavily cross-disciplined innovation processes. Interdisciplinary Journal of Information, Knowledge and Management, 5, 1-21.

Parzefall, M.-R., Seeck, H., \& Leppänen, A. (2008). Employee innovativeness in organizations: A review on the antecedents. Finnish Journal of Business Economics, 2, 165-182.

Patterson, M., West, M., Shackleton, V., Dawson, J., Lawthom, R., Maitlis, S., ... Wallace, A. (2005). Validating the organizational climate measure: Links to managerial practices, productivity and innovation. Journal of Organizational Behavior, 26(4), 379-408.

Paulus, P. (2000). Groups, teams and creativity: The creative potential of idea generating groups. Applied Psychology: An International Review, 49, 237-262.

Paulus, P., \& Brown, V. (2007). Toward more creative and innovative group idea generation: A cognitivesocial-motivational perspective of brainstorming. Social and Personality Psychology Compass, 1, 248265.

Perry-Smith, J., \& Shalley, C. (2003). The social side of creativity: a static and dynamic social network perspective. Academy of Management Review, 28(1), 89-106.

Reason, P., \& Bradbury, H. (2008). Introduction. In P. Reason, \& H. Bradbury (Eds.), The SAGE handbook of action research. Participative inquiry and practice (pp. 1-10). London: SAGE.

Sawyer, K. (2006). Educating for innovation. Thinking skills and creativity, 1(1), 41-48. 
Scharmer, C. (2001). Self-transcending knowledge: Organizing around emerging realities. In I. Nonaka, \& D. Teece (Eds.), Managing industrial knowledge: Creation, transfer and utilization (pp. 68-90). London: Sage Publications.

Shalley, C. (1995). Effects of coaction, expected evaluation and goal setting on creativity and productivity. Academy of Management Journal, 38, 483-503.

Shalley, C., \& Gilson, L. (2004). What leaders need to know: A review of social and contextual factors that can foster or hinder creativity. Leadership Quarterly, 15(1), 33-53.

Shalley, C., Gilson, L., \& Blum, T. (2000). Matching creativity requirements and the work environment: Effects on satisfaction and intentions to leave. Academy of Management Journal, 43, 215-223.

Taggar, S. (2002). Individual creativity and group ability to utilize individual creative resources: A multilevel model. Academy of Management Journal, 45(2), 315-330.

Tidd, J., Bessant, J., \& Pavitt, K. (2001). Managing innovation: Integrating technological, market and organizational change. Second edition, Chichester, UK: Wiley \& Sons ltd.

Tsoukas, H. (2009). A dialogical approach to the creation of the new knowledge in organizations. Organizational Science, 20(6), 941-957.

Uotila, T., Melkas, H., \& Harmaakorpi, V. (2005). Incorporating futures research into regional knowledge creation and management. Futures, 37(8), 849-866.

Van der Panne, G., van der Beers, C., \& Kleinknecht, A. (2003). Success and failure of innovation: A literature review. International Journal of Innovation Management, 7(3), 309-339.

Viitala, R. (2005). Johda osaamista! Keuruu: Otavan Kirjapaino Oy.

von Krogh, G., Ichijo, K., \& Nonaka, I. (2000). Enabling knowledge creation. Oxford: University Press.

Weick, K. (1979). The social psychology of organizations. Thousand Oaks, CA: Sage Publications.

Woodman, R., Sawyer, J., \& Griffin, R. (1993). Toward a theory of organizational creativity. Academy of Management Review, 18, 293-321.

\section{Biography}

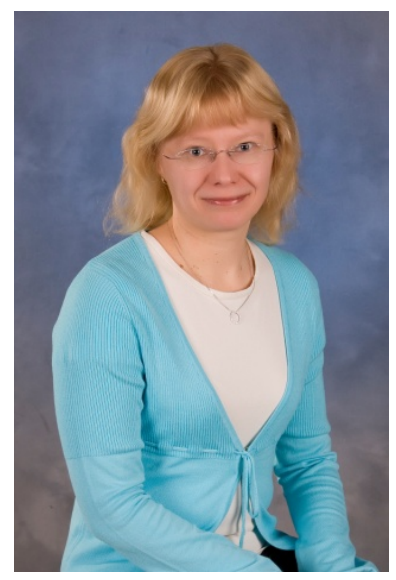

Satu Parjanen (M.Soc.Sc.) is a Researcher at Lappeenranta University of Technology, Lahti School of Innovation, Finland. Her research interests are related to brokerage functions and distances as sources of innovation. The theme of her post-graduate studies is collective creativity in practice-based innovation. She has published for example in European Journal of Innovation Management, International Journal of Innovation and Learning and European Planning Studies. 